\title{
Hume on Character, Action and Causal Necessity
}

\section{CLARENCE SHOLE JOHNSON}

Marianopolis College

1. In this paper, I will examine Hume's account of the causal relation between character and action in morality. ${ }^{1}$ Hume maintains that the relation between character and action is contingent, but I intend to show that his discussion suggests that the relation is necessary. ${ }^{2}$ And the necessity is not, as he believes, a psychological feature of spectator/ evaluators who would conclude, upon witnessing the performance of an action, that the agent of that action possesses a certain character trait.

${ }^{1}$ References to Hume are to the following texts:

- A Treatise of Hiuman Nature, 2nd ed. L.A. Selby-Bigge, revised by P. H. Nidditch (Oxford: Oxford Univ. Press, 1978); abbreviated as T, with page numbers given in parenthesis. The following alternative abbreviation is also used: T 11 , meaning Treatise Book I, Part I, Section I.

- An Abstract to A Treatise of Human Nature, referred to simply as Abstract; in the Selby-Bigge/Nidditch edition of the Treatise, with page numbers given in parenthesis.

-- Enquiries Concerning Human Understanding and Concerning the Principles of Morals, 3rd. ed., L.A. Selby-Bigge, revised by P.H. Nidditch (Oxford: Oxford Univ. Press, 1975); abbreviated as E, followed by page numbers in parenthesis.

${ }^{2}$ Similar conclusions as 1 will establish in this discussion have been arrived at, in a more general context, by Donald W. Livingston. See his "Hurne on Ultimate Causation," (American Philosophical Quarterly, Vol. 8, No. 1 JJanuary, 1971]), pp. 63-70; and Hume's Philosophy of Common Life (The Univ. of Chicago Press, 1984), chs. 6 and 7.

For discussions of other aspects of Hume's conception of character and action see the following: Rachacl Kydd, Reason and Conduct in Ilume's Treatise (London: Oxford Univ. Press, 1946), pp. 190-93; David Fate Norton, "Hume's Common Sense Morality," (Canadian Journal of Philosophy, Vol. 5, No. 4 (April, 1976]), Pp. 523-43, but see particularly pp. 526-30; Duvid Hume: Common-Sense Moralist, Sceptical Metaphysician (Princeton: Princeton Univ. Press, 1982), pp. 111-20; John Bricke, "Hume's Conception of Character," (South-Western Journal of Philosophy 5 (19741), pp. 107-13; and, finally, Pall S. Ardal, Passion and Vulue in Ilume's Treatise (Edinburgh: Edinburgh Univ. Press, 1966), pp. 91- 92; "Hume on Morality, Action and Character," read at the Twelfth Hume Conference held in Montreal, August, 1983. 
The necessity characterises a relation between an agent's possession of a determinate moral character trait and his performing certain correlative kinds of moral actions because of that character trait. In other words, the necessity in question is a feature of the agent by virtue of which the agent, already possessing a certain moral character trait, performs the kind of moral actions that follow upon that trait. I will argue that, on such a vicw, Hume's concept of causal necessity echoes, to borrow an expression of Davidson's, a logical necessity. ${ }^{3}$ My discussion will no doubt have significant consequences for Hume's overall conception of character, as well as his view of moral agency, his account of freedom in morality, and his thenry of moral responsibility. However, I will not examine those conscquences here. Instead, I will conclude with the observation that, despite his claim that the concept of necessity is univocal, being only psychological, Hume subscribes to conflicting accounts of causal necessity. And this, I will suggest, is because he is confused on the issue of causal necessity.

2. I begin with a brief summary of Hume's explicit account of the nature of causal relations in general in order to provide the background for the position I propose to defend.

At Treatise Book One, Hume says that all causal relations are based on, and reflect, four principles: contiguity in time and place, succession, constant conjunction and necessary connection. 4 To say of any two objects that they are contiguous is to say that they lie next to each other spatio-temporally, and that they therefore affect each other by their actions. For example, billiard ball $A$ induces motion in another billiard ball $B$ because the two billiard balls touch. Indeed, it is only because the two balls come together that one, by its action, affects the other.

Succession is the second principle that Hume says is essential to an analysis of causation. According to this principle, causes and their related effects do not take place simultaneously; causes take place before their effects and effects occur after their causes. Hume sums up the notion of

3Donald Davidson, "Hume's Cognitive Theory of Pride," (The Journal of Philosnphy, 73 (November 4, 1976)), p. 751.

${ }^{4}$ In the $\wedge b$ stract, Hume lists only three principles of causation; contiguity, succession and constant conjunction, saying that the concept of a cause is explicable only in terms of these three principles (T 649-50). But even so, he appeals to the principle of necessary connection in his analysis of the concept of a cause. As will emerge in the course of this paper, he thinks necessary connection presupposes constant conjunction. 
succession as "... that of PRIORITY of time in the cause before the effect" (T 75-76).

Third, the principle of constant conjunction. Hume says constant conjunction "implies no more than ... that like objects have always been Ifound to bel plac'd in like relations of contiguity and succession" (T 88). That is, our idea of constant conjunction presupposes that of contiguity and succession between objects. But Hume notes that there is more to constant conjunction than simply presupposing contiguity and succession. Constant conjunction also entails that like causes always produce like effects (T 649). 5 The overall importance of constant conjunction in Hume's theory of causation is brought out in his remark that if objects did not have a regular and uniform conjuction with each other, which conjunction we then perceive, we would never have had a notion of causal relations (T 400).

Finally, the notion of necessary connection. There are those like Locke and Malebranche, Hume charges, who regard necessary connection as a property in objects in virtue of which objects produce the kind of effects they are known to produce (T 157-68; cf. 90-91). Hume dismisses this view arguing, among other things, that if there was such a property in objects we should have some sense impression of it as we do of the already known properties of objects. Moreover, our idea of necessary connection should derive from that impression. However, there is no impression "convey'd by our senses" from which we acquired the notion of necessary connection, he says, and the reason there is no such impression is that there is no property in objects that can produce it (T 165-66). Therefore, he concludes, Locke and Malebranche are mistaken in their views of necessary connection, and our idea of necessary connection has to be accounted for otherwise.

Hume offers his own account of necessary connection, namely, that to speak of a necessary connection is to speak of a habit that we have, as observer/evaluators, to infer the occurrence of a member of a conjunctive pair from the actual or potential occurrence of the other member. As observer/evaluators, says Hume, we acquire this habit through experience, after we have witnessed a constant conjunction between pairs of object-e.g. lightning and thunder. We then naturally come to expect

${ }^{5}$ The entailment may also go the other way, as was pointed out to ine by the referee of this paper for the 1987 meetings of the Canadian Philosophical Association. (I later learnt that the referes was John I'. Wright. See also note 13) 
either member upon the putative appearance of the other. Consequent upon this expectation, we always readily infer the occurrence of one member from the occurrence of the other. It is this propensity in us to draw inferences about members in a conjunctive set that Hume charactcrises as a necessary connection. (In consonance with his empiricist maxim that all ideas be traced to an antecedent impression, Hume identifies this mental propensity with a reflective impression, thus providing the impression from which he says originated our idea of necessary connection.) Accordingly, he defines necessary connection as "nothing but that determination of the thought to pass from causes to effects and from effects to causes, according to their experienc'd union." Indecd, in summing up his view of causal necessity, Hume says that necessity is "something, that exists in the mind, not in objects. .." (T 165-66; 400 and 408 ).

3. From this summary of the central features of Hume's theory of causation it can be scen that he thinks causal relations are contingent and not necessary. Hume says in the Abstract that "The mind can always conceive any effect to follow from any cause, and indeed any event to follow upon another ..." (T 650, emphasis in text). It is not surprising, thercfore, that in his account of the relation between character and action, in particular, Hume simply speaks of the constant union of particular motives (or character traits) and the particular actions they direct, of particular actions "being constantly united with their proper motives" (T 401, 404, 661), thus reflecting his basic claim that all causal relations are contingent. On Hume's explicit view, then, it seems logically conceivable that particular forms of behaviour which usually originate from specific moral character traits be produced by features of persons other than those character traits. For example, the form of behaviour we normally describe as virtuous-i.e. when it originates from a virtuous character trait-can conccivably be produced by any but such a trait. Of course, Hume would not characterise such behaviour as virtuous. But this, as I will argue, is because he regards a moral action to be a specific kind of behaviour, one that is necessarily (in the non- psychological sense) connected with its cause. And it is this conception of causal necessity that contravenes his official thesis. For the present, however, I wish also to point out that Hume, consistent with his official position, believes that character traits may exist without ever giving rise to their correlative moral actions, even when all the relevant conditions obtain. These include: (a) the existence of the situation requiring action; (b) the agent's perception or recognition of 
the situation; and (c) the absence of external constraints on the agent. ${ }^{6}$ He describes a situation (to which I shall again refer) in which a person purportedly virtuous is incapacitated by such circumstances as isolation in a desert or imprisonment in a dungeon from manifesting his virtuousness in action ( $T$ 584).

The question that immediately arises is whether or not Hume's discussion of the causal relation between character and action show the relation to be contingent as he might want us to believe. This question is easily given a negative answer as soon as one attends to his account of the nature of liberty and necessity given at Treatise 231 and 232 . In that discussion Hume endeavours to show that, contra the libertarians, human actions are causally determined, and he begins with an account of the nature of the actions of material objects, explaining that whatever observations he makes about the behaviour of material objects will also be true, mutatis mutandis, of the conduct of human beings (T 403). Accordingly, he directs attention to the generally acknowledged view about the nature of the actions of material objects, namely, that "the actions of external objects are necessary, and that in the communication of their motion, in their attraction, and mutual cohesion, there are not the least traces of indifference or liberty." Subscribing to that view, Hume says that

Every object is determin'd by an absolute fate to a certain degree and direction of its motion, and can no more depart from that precise line, in which it moves, than it can convert itself into an angel, or spirit, or any superior substance. The actions, therefore, of matter are to be regarded as instances of necessary actions; and whatever is in this respect on the same footing with matter, must be acknowledg'd to be necessary (T 399 . 400).

I will first bring out a major implication of Hume's view in the abovequoted passage for his overall conception of causal determination and then go on to review his account of the causal relation between character and action. To that end I want to note at once that, contrary to Hume's explicit view in which causal necessity is defined in psychological terms, the sense of causal determination (or necessitation) in this passage is etiological with logical overtones. Hume is making a point about the kind

${ }^{6}$ Cr. Bricke, "Hume's Conception of Character," pp. 109-10. 
of bchaviour that material objects are incapable of exhibiting-namely, purposive behaviour---because of their nalure as inanimate entities. (And by implication it is a statement about the kind of behaviour that material objects can exhibit.) A material object, he says, "can no more depart from that precise line in which it moves, than it can convert itself into an angel, or spirit, or superior substance." The suggestion in this statement is, clearly, that it is impossible for material objects to exhibit purposive forms of behaviour just as it is impossible for them to transform themselves into superior non-material entities. But, contra what Hume might think, the impossibility he is describing is not empirical. In other words, Hume is not saying that it is a contingent fact that an object endowed with only material-object attributes exhibit non-purposive forms of behaviour, but that such an object could (conceivably) exhibit purposive forms of bchaviour. His claim is much stronger: on the one hand, he is saying that the forms of bchaviour material objects exhibit cannot but be what they are given the nature of those objects; or, more succinctly, that the bchaviour of material objects is ontologically rooted in the kind of characteristics possessed by (and essential to) those objects. And on the other hand he seems to be suggesting that it is logically impossible for a material object, being the kind of entity it is, to exhibit forms of behaviour that cannot conceivably originate from the kind of characteristics with which entities of that kind are endowed. This logical impossibility comes out, I suggest, in Hume's statement that if material objects can conceivably exhibit purposive forms of behaviour then they can also transform themselves into superior non-material entities. Hume is certainly asserting the contrapositive of this view, namely, that material objects can do neither. Of course, on such a view it may be contingent that material objects possess material-object characteristics but not that they exhibit non-purposive conduct. I submit that this is the reason Hume describes the behaviour of material objects as being determined "by an absolute fate." As will be scen shortly similar considerations will apply to bcings which exhibit purposive conduct, in particular, humans.

It might perhaps be said that, barring the passage on which I have based my argument, Hume is otherwise consistent in his psychological account of causal necessity. In the paragraph immediately following the section I claborated, the objection might continuc, Hume insists that necessity is nothing but an inference of the mind brought about by our experiencing a constant and regular sequence. Moreover, he there makes explicit that only two factors are essential to necessity: the constant conjunction and the inference of the mind. Thus, my claim that he offers a non-psychological account of causal necessity is inaccurate. 
But this objection, far from redeeming Hume, provides a basis for one to argue that he is confused over the issue of causal necessity. For he seems to be simultaneously explaining necessity in terms of the property of objects and declaring that necessity is nothing but an inference of the mind. His discussion in the passage I cited above clearly shows him deviating from his psychological account of causal necessity. His concern in that passage is with the nature of material objects and not with the mental operations of observer/evaluators who may (or may not) have observed those objects. On this new view, material objects will, it serms, exhibit non-purposive forms of behaviour whether or not there are sentient beings to observe them. Moreover, material objects cannot even be conceived to exhibit any but non-purposive forms of behaviour. Because the necessity in question is anything but a mental determination of observer/evaluators the conclusion one must draw is that, despite Hume's explicit assertions to the contrary, he does put forward an account of causal necessity that is non-psychological; an account in which causal necessity is etiological, meaning that the necessity is grounded in the nature of material objects. Moreover, this etiological account of causal necessity has overtones of a logical necessity.

4. Doubtless, Hume is unaware that he advances this etiological/logical account of causal necessity, for he maintains that necussity is a univocal concept characterising the mental operations of human beings who may have observed regularly conjoined states of affairs:

The necessity of any action, whether of matter or of the mind, is not properly a quality in the agent, but in any thinking or intelligent being, who may consider the action, and consists in the determination of his thought to infer its existence from some preceding objects ( $T$ 408, emphasis added).?

Hume even intends his illustrations of causal necessity to uphold this view. For example, in Treutise Book One, he remarks that a traveller who encounters a river stops in his tracks because he "foresees" the consequences of his proceeding forward (T 103). Hume advances a similar

${ }^{7}$ Cf. Hume's remark in Book One:

... there is but one kind of necessity, as there is but one kind of cause, and that the common distinction betwixt moral and physical necessity is without any foundation in nature (T 171, emphasis in text). 
view in Book Two, in saying that a prisoner without wealth or connection soon "discovers" that, unless he breaks down the walls and bars surrounding him, it is otherwise impossible for him to be out of prison. And that very prisoner, Hume continues, upon being conducted to the scaffold, "foresces" his death with certainty both from the constancy and fidclity of the guards and from the axe or wheel to be used to exccute him (T 406).

These illustrations rightly uphold Hume's explicit view that necessity is a psycholngical feature of human beings who may have directly or indirectly experienced certain regularly conjoined sequences of events or states of affairs. But for all that Hume keeps using necessity in at least the non-psycholngical/ etiological sense I have claimed, as is evident from the following passage:

\begin{abstract}
We must certainly allow, that the cohesion of the parts of matter arises from natural and necessary principles, whatever difficulty we may find in explaining them: And for a like reason we must allow, that human socicty is founded on like principles; and our reason in the latter case, is better than even that in the former; because we not only observe, that men always scek socicty but can also explain the principles, on which this universal propensity is founded (T 401-02, all but last emphasis added).
\end{abstract}

The necessary principles of which Hume speaks in this passage are not the features of sentient beings involving the drawing of causal inferences. Rather, they are characteristics of entities, material objects and human beings, which make each of those kinds of entities behave as they do. Material objects exhibit non-purposive forms of behaviour because of the kind of attributes with which they are endowed. And human beings come together to form societies because, as Hume himself says clsewhere, individually, man is naturally incapable of providing for all his needs. "'Tis by society alone he is able to supply his defects, and raise himself up to an equality with his fellow creatures (i.e. the lower animalsl, and even acquire a superiority above them" (T 485). In both cases, the necessity in the behaviour of the entities in question is etiological. 8

8It is worth pointing out that Hume speaks of certain "secret powers," certain "natural powers and principles" that material objects possess, powers and principles that, according to him, make material objects 
5. In light of the preceding discussion I want now to review Hume's conception of the causal relation between character and action. I will concentrate only on his discussion of the character trait of virtuousness and its relation to virtuous actions, but the considerations I will bring to bear on my review can also be applied, with appropriate adjustments, to Hume's entire catalogue of moral virtues and vices. To begin, then, 1 will cite a few passages from Treatise 331 which suggest that, according to Hume's discussion, the relation between virtuousness and virtuous actions is necessary, and that the necessity is in the first place etiological. According to Hume,

Where a person is possess'd of a character, that in its natural tendency is beneficial to society, we esterm him virtuous, and are delighted with the view of his character, even tho' particular accidents prevent its operation, and

behave as they do. Hume even speaks of a harmony that nature has "established among external objects" by endowing those objects with secret powers and principles. Cranted, he says also that "we are ignorant of those powers and forces" governing the regular course of the behaviour of those entities (E 30-42; 55; and T 652). But these remarks simply show that he is confused on the subject of causal necessity, because while denying that necessity is a feature of entities, he is at the same time expressing the contrary view.

John P. Wright fails to see this confusion in Hume when he says that Hume never denied that causal necessity is a feature of entities. According to Wright, Hume says only that "we have no idea of necessity, power or agency of causes, not that there is no necessity, power or agency in the objects themselves" (The Sceptical Realism of David Ilume [Manchester: Manchester Univ. Press, 1983] p. 132, emphasis in text). It seems to have completely escaped Wright that any such claim made by Hume is inconsistent with Hume's official position, as summed up in passages I have cited showing that he thinks necessity is a univocal concept. Indeed, that Hume is adamant on this issue can again be seen very clearly when one considers his view of moral necessity (or, as he calls it, moral evidence). He defines moral necessity as "nothing but a conclusion concerning the actions of men, deriv'd from a consideration of their motives, temper and situation," and goes on to say that natural and moral evidence "aptly ... cement together" to form one chain of argument between them (T 404, 406). The chain of argument of which he is liere speaking is that causal necessity is a mental feature of spectator/evaluators. 
incapacitate him from being serviceable to his friends and country. Virtue in rags is still virtue; and the love, which it procures, attends a man into a dungeon or desart, where the virtue can no longer be exerted in action, and is lost to all the world.

In the succeding paragraph Hume reinforces this view arguing that, although " Tis sufficient if every thing be compleat in the object itself," we do not ccase to approve of a person with a virtuous character because he can no longer exercise his virtuousness in action. ${ }^{9}$ Hume of course observes that we are "more affected" by a person's character when that character can be put into action than when it remains simply a potentiality. But even so, he argues, "we do not say that it the exerted characterl is more virtuous, In]or that we esteem it the more." He illustrates this point by saying that we feel pleased with a house that is designed to accommodate all aspects of life, although we are also aware that no one will ever occupy it. Similarly, we are delighted with a country whose land is potentially fertile and climate potentially good when we consider the happiness such a country would provide for its inhabitants, all the while cognisant of the fact that the country is at present both a descrt and is uninhabited (T 584-85).

Throughout this discussion Hume's explicit concern is with the sentiment of esteem and approval that we, as spectator/evaluators, normally feel towards a person whom we already know to be virtuous, even though that person may never again perform virtuous actions. (See also his discussion at $T$ 348-49.) But a careful examination of the passages reveals that he is concerned also, albeit implicitly, with virtuousness itself, as a moral quality in a person, a quality that both inheres in a person and would causally direct that person's morally significant actions whether or not there are spectators. Consider his assertion that "Virtue in rags is still virtue; and the love, which it procures, attends a man into a dungeon or desart, where the virtue can no longer be exerted in action, and is lost to all the world" (Emphasis added). According to this statement, a person does not cease to be virtuous because he is locked up in a dungeon or is

${ }^{9}$ The passage continues:

...where any object, in all its parts, is fitted to attain an agrceable end, it naturally gives us pleasure, and is esteem'd beautiful, even tho' some external circumstances be wanting to render it altogether effectual (T 584). 
isolated in a desert. On the contrary, he continues to be virtuous, and because of this, his virtuousness, although a potentiality, still affects us: it elicits our esteem for, and approval of, the person as if the person was actually capable of performing virtuous actions. To say however that a person is still virtuous when his virtuousness is lost to all the world, is to say that he is characterised by certain moral properties that would causally direct him to perform virtuous actions when the situation requiring that he do so exists and all other conditions are fulfilled. Moreover, the person's performance of those actions is not contingent upon the presence of spectator/evaluators. Regardless of the presence (or absence) of spectator/ evaluators, he would perform those actions. Indeed, Hume's general position is that virtuousness, as a moral character trait, or a relatively permanent mental feature imbued with a specific moral quality, inheres in a person as the quality redness (say) inheres in a substance (a book, for example). And the person's possession of this moral feature is a necessary (even though not a sufficient) condition for him to exhibit the specific kind of morally relevant form of behaviour called a virtuous action, when appropriate conditions obtain.

As in the case of material objects, the causal direction here is etiological with logical overtones. The causal direction is etiological because, for Hume, virtuous actions have their ontological basis in virtuous character traits. Hume's discussion of the nature of moral action makes this point even clearer. He believes that a given form of behaviuur qualifies as a morally relevant action if and only if it is produced by, and hence is reflective of, a specific moral feature in a person. Thus he writes:

If any action be either virtuous or vicious, 'tis only as a sign of some quality or character. It must depend upon durable principles of the mind, which extend over the whole conduct, and enter into the personal character. Actions themselves, not proceeding from any constant principle, have no influence on love or hatred, pride or humility; and consequently are never consider'd in morality (T 575, emphasis in text; cf. 348-49, 479 and 411).

Hume even regards morally relevant actions as effects of mental features that have moral qualities, mental features that are character traits. He repeatedly says moral actions "proceed from," and are therefore "signs or indications" of, durable mental principles that comprise a person's character. Accordingly, he argues that, given that a person is characterised by a virtuous mental quality--meaning that a person has a 
virtuous character trait-it is the mental quality that directs the person's virtuous actions and actually "bestows" a like moral quality on them $(T$ 477-78, cf. 575). Saying then that a given form of behaviour is a virtuous action entails that the behaviour is endowed with the moral quality of virtuousness; in fact, that it "derive[s]" its virtuousness from a specific mental / moral feature of the person (T 478).

One is to conclude from such a view that the performance of any moral action, in this case a virtuous action, presupposes the existence in the agent of the appropriate character trait that singularly gives rise to that action. Thus, given that a person lacks a virtuous character trait it is in no way possible for him to perform a virtuous action; not the relevant kind of action that can, in Hume's sense, only be performed by a person with a virtuous character trait. Alternatively put, virtuousness is the property in the absence of which a person cannot possibly perform virtuous actions, or that any action he produces be the same as that which could be produced by a person endowed with that character trait. And more generally, inasmuch as Hume views moral actions as effects of specific moral causes, it is just not possible that those moral effects be produced by anything other than their respective moral causes. Conversely, given that a certain character trait exists, then necessarily, it would give rise to the kind of actions that it alone produces, when all the relevant conditions are satisfied, including the agent's perception of the situation in which he should act. I speak of a necessity in the performance of moral actions because Hume thinks that the exercise (or manifestation) of character traits in action is a response that naturally ensues from agents when the latter are in appropriate situations and all other relevant conditions are fulfilled. 10 He says at Treatise 321 that our ascriptions of blame are made always on the supposition that the agent whose conduct is being evaluated failed to perform the kind of action he ought to have performed in the given situation. And this failure reflects the agent's lack of the appropriate character trait (or motive) that should

${ }^{10} \mathrm{~A}$ comparison can here be made between an agent's performance of a moral action, wherein that performance is a rcaction to a specific (actual or putative) state of affairs, and the arousal of the moral scntiments in an impartial spectator, the sentiments through which that spectator feels moral approval and disapproval in reaction to instances of virtue and vice. According to Hume, cach moral sentiment "arises" (T 469, 472); it "ensues" (E 290); and we "naturally" and "unavoidably feel" it "given the structure of human nature" (T 466, E 293). 
have directed him to act. ${ }^{11}$ For this reason we find the agent morally culpable for his failure to act. On the other hand, Hume continues, we retract our blame if we discover that the agent had the character trait in question but, "by some circumstances [hitherto] unknown to us," was hindered from manifesting that trait in action (T 477-78). Of course, Hume is assuming that we normally hold persons responsible for their lack of certain character traits, otherwise he would not say that we blame a person for his failure to perform actions directed by a given character trait. But I will not pursue this matter here as it is not central to my concern. What I wish to bring out by citing these remarks is that Hume, by his view that when we assign blame to a person for failing to perform an action we are in fact blaming him for his lacking the character trait which directs that kind of action, seems to be implying that if the person had had the character trait he could not but have performed the required action. And in that case we would have praised him.

If this is a correct interpretation of Hume then, on his view, a virtuous person cannot but respond to a putative case of suffering when he perceives the situation correctly and is not constrained by external factors. Indeed, it would seem that, for Hume, a ground for withholding virtuousness to a person is for the person to fail to perform the relevant kind of action when appropriate circumstances obtain, he perceives the situation correctly and is not constrained by unfortunate circumstances. It is for this reason that I think it accurate to say that Hume's discussion suggests that virtuous actions are etiologically necessitated by virtuous character traits. As I have already remarked, regardless of the presence of spectator/evaluators, a virtuous person cannot but perform virtuous actions in appropriate situations. But the necessity is also logical because a contradiction would follow in saying that a virtuous action can exist in the absence of a virtuous character trait. In Hume's theory, a form of behaviour may, in every respect except origin, resemble another that originates from a virtuous character trait. The former is not, however, a

${ }^{11}$ It is of course debatable that Hume gives motive and character the same signification, but I will not go into that matter here. I assume that he treats both these terms as equivalent, cognisant of the fact that he is not altogether clear on his uses of the term motive. For example, he at times uses motive to mean an actuating principle, as when he speaks of reasun and passion as the "influencing motives of the will" (T 413). But he also speaks of the mental items that qualify us for moral praise and blame as motives, as in the passage in question. Further, he speaks of rewards and punishments as motives to moral good and away from moral evil, respectively (T 410 and 609 ). 
virtuous action. The reason for this is that he has a very strict conception of moral action, according to which a form of behaviour qualifies as a moral action if and only if it is imbued with, and hence reflects, a specific moral quality in a person's character. This conception of a moral action logically prohibits him from saying that character and action, qua items in a causal chain, are contingently related. The contingency thesis of causation implics that we can conceive of a moral action as originating from a source other than that alone which produces it and which it externalizesan implication Hume explicitly rejects. But in rejecting this position (which is the logical consequence of his official doctrine), and in maintaining the strict conception of moral action I have claimed, Hume is tacitly advancing the view that the causation between character and action is necessary in a non-psychological sense. Indeed, it is only on the basis of this view of necessity that we can make intelligible his assertion that a person's action is evidence of his character and, more importantly, that a person, in being morally appraised for his actions, is in fact being morally appraised for his character (T 411, 477-78, and 575). 12

6. I have shown that, according to Hume's discussion of the relation between character and action, the moral actions a person performs have

${ }^{12}$ Some may say that the contingency thesis implies only that while a virtuous action is necessarily the product of a virtuous character-since this is what it means to call an action virtuous in Hume's system-- the converse need not necessarily obtain. That is, a virtuous character need not necessarily produce virtuous actions. Cognisant of this point, I insist nevertheless that the proper way of expressing Hume's view of the relation between character and action is that an action is virtuous if and only if (and not simply only if) it is produced by the appropriate character trait. My reason for this view is that much else that Hume says both about the nature of moral action and of the relation between character and action is at variance with the general claims of the contingency thesis. Indecd, a reason for not adopting that thesis here is that it would commit Hume to the view that moral actions can conceivably be produced by features of agents other than their moral characters. For, be it remembered, the thesis is that events, or more generally states of affairs in the world, are all loose and unconnected; there is nothing that cements any two natural phenomena together, hence anything might arise from anything! Hume's discussion seems, however, to reject this fundamental tenet of the contingency thesis of causation. Moreover, his theory of moral valuation is intelligible precisely because it depends on a conception of the relation between character and action that cuts across his own radical and oft-cited view of the constant but contingent union of the items in a causal relation. 
their logical and ontological basis in the mental features that comprise the person's character, mental features given which the person performs certain kinds of actions, and in the absence of which he cannot conceivably perform those kinds of actions. In my view, this suggests that, notwithstanding Hume's official pronouncements to the contrary, the relation between character and action is both etiologically and logically necessary. However, I do not mean to deny validity in the psychological sense of necessity which Hume has in mind in asserting that it is upon the principles of necessity that persons are ascribed merit or demerit for their actions (T 411, cf. 404-05). Hume is clearly correct in saying that our ascription of moral epithets to persons is based on experience, in the sense that we already know from experience that particular kinds of actions only derive from particular kinds of character traits with which they are constantly conjoined. Thus, when we experience an instance of a certain kind of action, a virtuous action, for example, we conclude that the agent of that action is virtuous, meaning that he has a virtuous character trait. But my point is that this is not the sense of causal necessity that comes through in his discussion of the behaviour of entities as instances of necessary actions. His discussion of the relation between character and action in morality shows this relation to be necessary, but the necessity characterises a person's possession of determinate moral features and his performing certain correlative kinds of moral actions because of those moral features. Thus, the kind of character trait a person has may indeced be contingent, but not the kinds of actions he performs by virtue of his character trait. Hume's claim, then, that causal necessity here, as elsewhere, is a psychological phenomenon that occurs in spectator/ evaluators is clearly mistaken. The conclusion I will therefore draw from my discussion is that there is a discrepancy between Hume's explicit claim about, and his discussion of, the causal relation between character and action. His explicit claim is that "There is no object [event, state of affairs], which implies the existence of any other if we consider these objects [events, states of affairs] in themselves, and never look beyond the ideas which we form of them" (T 86-87). But his discussion commits him to the stronger view that there are some objects or states of affairs, namcly, character and action, that imply the existence of others. The discrepancy between Hume's explicit claim and his implicit commitment is, in my view, evidence that (i) he is confused about the issue of causal necessity, because while outrightly rejecting the Lockean and Cartesian views he is 
tacitly advancing a similar view; and that (ii) the concept of necessity is not univocal even in his own system. 13

${ }^{13}$ This paper was originally presented at the 31st Annual Meetings of the Canadian Philosophical Association in Hamilton, Ontario, 24th-27th May, 1987. I am grateful to David Norton and Harry Bracken for helpful comments on an earlier draft. I am also grateful to the reviewers of Auslegung for comments which I found very helpful in my discussion of the nature of moral action in Hume's thought. 